\title{
Measuring the environmental goods and services sector
}

\author{
Donna Livesey
}

Office for National Statistics

\section{Summary}

There is a clear requirement in the UK, and internationally, to measure the progress towards a 'green' economy, and within this to understand the contribution of the environmental goods and services sector to the economy and the potential for growth. As stated in the UK Environmental Accounts Strategy published in June 2010, ONS is conducting a study to assess the feasibility of measuring this sector in line with the definitional framework proposed by Eurostat. This article presents the framework and outlines a number of interesting statistical challenges to be examined as part of the study, the results of which will be published in summer 2011.

\section{Introduction}

This is the first of two articles on measuring the environmental goods and services sector in the UK. This first article introduces the work being taken forward by the ONS to measure this sector, sets it in a UK and international context and discusses the challenges ahead. A second article, scheduled for summer 2011, will present results from the feasibility study and proposals for follow up work which would be required in order to deliver regular official statistics. This feasibility study forms part of the prioritised work programme outlined in the UK Environmental Accounts Strategy ${ }^{1}$ published by ONS in June 2010.

There is increasing economic and political interest in the green economy, the low carbon economy, and the environmental goods and services sector with the global economic downturn having served to sharpen the focus on the potential for green growth.

Within the context of delivering sustainable economic growth, for example, HM Treasury's 2010 Spending Review' ${ }^{2}$ included decisions targeted to 'position the UK at the forefront of the transition to a low carbon economy'. Also in October, David Cameron's speech to the $\mathrm{CBI}{ }^{3}$ on 'creating a new economic dynamism' talked of investment in the UK offshore wind industry as 'a triple win' stating that 'it will help secure our energy supplies, protect our planet and....could create 70,000 jobs'. 
In the UK, and globally, questions are being posed that have both environmental and economic sustainability at their heart. At the macro-level these questions focus on issues such as the size of the environmental goods and services sector, the contribution to the wider economy, the relative productivity of low carbon and traditional industries and competitiveness in the global market. The potential for growth and increased numbers of 'green' jobs are key points of interest together with the challenges of minimising the impact of the economy on climate change and decoupling economic growth and reliance on finite oil and gas reserves.

There is a recognised requirement for an evidence base to inform planning and cost-benefit analyses and to understand if environmental policy and investment decisions are having the desired impact on targets for reducing greenhouse gas emissions, making the switch to renewable energy sources and job creation.

Internationally, the need for comparable statistics on the environmental goods and services sector is well established. Work by the OECD and European Commission to develop the framework for such statistics began in the early 1990 s and a series of reports and country studies have since been published. In 2009, Eurostat (Statistical Agency of the European Commission) published a data collection handbook ${ }^{4}$ to support National Statistics Institutes (NSIs) in the collection of official statistics and standard tables ${ }^{5}$ were established for an EU pilot data collection. A number of countries have already taken part in pilot studies and preliminary results are now available (Table 1).

\section{Table $1 \quad$ Turnover and employment in the environmental goods and services sector}

\begin{tabular}{lcc}
\hline Country & Turnover (Euro billions) & $\begin{array}{c}\text { Employment (full-time equivalent, } \\
\text { thousands) }\end{array}$ \\
\hline Germany (2007) & 4.6 & 76 \\
France (2007) & 1.0 & 209 \\
Netherlands (2007) & Not available & 8 \\
Austria (2008) & Not available & 76 \\
Poland (2007) & 2.9 & 262 \\
Romania (2006) & 2.1 & 123 \\
Sweden (2006) & 1.0 & 35 \\
\hline
\end{tabular}

Source: Adapted from Eurostat, September 2010

Confirming the importance of such statistics within Europe, draft amendments have been tabled to the proposal for a new Regulation on Environmental Economic Accounts currently going through the European Parliament and Council co-decision procedure to include the measurement of the environmental goods and services sector in a list of statistical modules for development '... as a matter of priority'. (2010/0073 (COD) 9 November 2011) 
At the same time, the United Nations Statistics Division has a global consultation underway on the UN System of Environmental Economic Accounting (UNSEEA) ${ }^{6}$ and is proposing that the measurement of the environmental goods and services sector, based on the methodology outlined in the Eurostat Handbook, forms part of the core international standard on environmental economic accounting. This standard, once approved by the UN Statistics Commission, would sit alongside the UN System of National Accounts ${ }^{7}$ and provide the framework for international statistical reporting.

This article outlines the concepts and definitions underpinning the proposed international standards, describes the current position in the UK and introduces the feasibility study which ONS is undertaking. Based on a review of international experience and consultation carried out to date by ONS within the UK, some of the key issues to be examined by the study are discussed.

Preliminary results from the feasibility study will be published in summer 2011 and a crossgovernment working group will steer the project. Through this early article, ONS is seeking to raise awareness of this project with a wider audience of potential users of these statistics and would welcome hearing from those with an interest in any of the issues raised.

\section{Concepts and definitions}

This article began by quoting commonly used phrases such as green economy and green growth but how is the environmental goods and services sector that the ONS is seeking to measure defined within this wider context?

In 2009, the OECD Ministerial Council endorsed a mandate for the OECD to develop a Green Growth Strategy 'bringing together economic, environmental, social, technological and development aspects into a comprehensive framework'. (OECD, 2009).

The OECD describes green growth as:

'... a way to pursue economic growth and development, while preventing environmental degradation, biodiversity loss and unsustainable natural resource use. It...aims at identifying cleaner sources of growth, including seizing the opportunities to develop new green industries, jobs and technologies, whilst also managing structural changes associated with the transition to a greener economy. Managing the employment and other distribution effects of change in more traditional sectors will also need to go hand in hand with exploiting new opportunities'.(OECD 2010)

Part of the ongoing OECD programme of work is focused on establishing how to measure progress towards green growth and a greener economy, including the development of key indicators covering environmental efficiency of production and consumption, the natural asset base of the economy, environmental quality of life and indicators describing policy responses and instruments.

The concepts of green growth and the green economy relate to changing the face of the whole economy. The aim of the ONS feasibility study to measure the environmental goods and services 
sector addresses one specific element of this. The environmental goods and services sector as defined by the Eurostat Handbook is reproduced in Box 1.

\section{Box 1 Definition of the environmental goods and services sector ${ }^{*}$}

The environmental goods and services sector consists of a heterogeneous set of producers of technologies, goods and services that:

- measure, control, restore, prevent, treat, minimise, research and sensitise environmental damages to air, water and soil as well as problems related to waste, noise, biodiversity and landscapes. This includes 'cleaner' technologies, goods and services that prevent or minimise pollution

- measure, control, restore, prevent, minimise, research and sensitise resource depletion. This results mainly in resource-efficient technologies, goods and services that minimise the use of natural resources

These technologies and products (goods and services) must satisfy the end purpose criterion, meaning they must have an environmental protection or resource management purpose as their prime objective.

Note

* The Environmental Goods and Services Sector, A Data Collection Handbook, Eurostat (2009)

For the purposes of delivering internationally comparable official statistics a common definitional framework is critical. The Eurostat handbook expands on the core definition but key concepts are as follows:

- 'Heterogeneous set of producers' confirms that the sector cuts across the economy to include the activities of public and private enterprises and government

- The 'environmental protection or resource management purpose' must be the main purpose, classified primarily by the technical nature of the good or service. The example given in the Eurostat handbook is the provision of waste management services. The key driver for the producers of waste management services is not to protect the environment, yet from a technical stance, the services remove waste from the environment and so meet the definition. Where the classification of specific cases cannot be resolved, the intention of the producer in delivering the good or service is taken into account. The intention of the consumer is not considered, nor is the benefit to the environment considered in isolation if the main purpose of the activity is to meet a technical, human or economic need rather than an environmental one. Music downloading services, for example, could be considered environmentally beneficial as they substitute for the production and transportation of CDs, but the main purpose is not environmental protection or resource management. 


\section{Table 2 Dimensions of the Eurostat pilot data collection}

1. Variables

\author{
Employment
}

Turnover

Value added

Exports

2. Technologies,

Environmental specific goods and services

\author{
services
}

Connected products

End of pipe technologies

Integrated technologies

Adapted goods

3. Producers

Corporations

General Government

Principal and secondary

Ancillary

5. Environmental domains

6. Industry
Full-time equivalent

Totals invoiced, corresponds to market sales of goods and services supplied to third parties. For non-market producer estimated as total costs of production

Difference between the value of the output and the sum of all intermediate consumption

Sales, barter, gifts or grants of goods and services from residents to non-residents

Output of environmental protection and resource management 'characteristic' activities. e.g. design of systems to treat exhaust gases from motor vehicles

Goods and services which are not typical of environmental protection or resource management but directly serve these activities and have no other use. e.g. installation of equipment for air pollution treatment

Mainly technical installation and equipment produced for measurement, control treatment and correction. e.g. equipment for air pollution treatment

Technical processes, methods and knowledge used in production processes which are less polluting and resource intensive. e.g. equipment that produces less exhaust gases to be treated

Primary use is not environmental protection or resources management. These are goods which are less polluting or more resource-efficient than equivalent standard goods performing a similar function. e.g. less polluting goods such as de-sulphurised diesel

All economic activity not belonging to general government. Includes public corporations. Excludes households

Central and local government

The principal activity is that producing the largest share of the value added. Secondary activities produce a smaller share

Exist solely to support the main productive activities of an entity by producing goods and services solely for the use of that entity e.g. in-house waste collection, production of renewable energy for internal consumption

Environmental protection Based on the Classification of Environmental Protection Activities (CEPA) ${ }^{8}$ and is composed of protection of ambient air and climate, wastewater management, waste management, protection and remediation of soil, groundwater and surface water, noise and vibration abatement, protection of biodiversity and landscape, protection against radiation, research and development and other environmental protection activities. Each is to be reported separately with a further breakdown for the protection of climate and ozone layer

Resource management Based on the Classification of Resource Management Activities (CREMA). ${ }^{9}$ This does not yet constitute an international standard. Management of waters, management of forest resources, management of wild flora and fauna, management of energy resources (production of energy from renewable resources, heat/energy saving and minimisation of intake of fossil resources for non-energy uses), management of minerals, research and development and other natural resource management activities

NACE Rev.2 2-digit level NACE Rev. $2^{10}$ is the latest revision of the European Union's industrial classification system. NACE Rev. 2 is consistent with the UK System of Industrial Classification 2007 $(\mathrm{SIC} 2007)^{11}$ down to the 4-digit level. 
Such exclusions are critical to our understanding of the scope of the sector. Another key exclusion is activity 'aimed mainly at preventing or reducing the impact of natural disasters such as storms or volcanic eruptions on human activities' (Eurostat, 2009) as it is assessed that protection of humankind is the key driver.

Table 2 summarises the data requirements of the Eurostat pilot data collection, including the types of goods and services covered. As part of the feasibility study, ONS will be seeking to populate the questionnaire as far as possible, assess the quality of the data provided and identify how any gaps can be filled moving forward.

\section{Current status in the UK}

The UK publishes regular Environmental Economic Accounts ${ }^{12}$ as 'satellite accounts' to the main UK National Accounts ${ }^{13}$, measuring the environmental impact of UK economic activity. In June 2010, ONS published a strategy for the continued development of these accounts. This strategy reflects the requirements of emerging international standards and the proposed European regulation as well as the findings of the Report on the Measurement of Economic Performance and Social Progress (Stiglitz et al, 2009) ${ }^{14}$ which, in part, provided the stimulus for the development of measures of national well-being announced by the Prime Minister and National Statistician on 25 November ${ }^{15}$.

Whilst the UK has contributed to the development of the proposed international standards and guidance on measuring the environmental goods and services sector, statistics in line with these standards have yet to be compiled by ONS. The study to assess the feasibility of establishing such statistics therefore forms part of the prioritised work programme outlined in the strategy.

That is not to say, however, that this is a new concept in the UK. A stakeholder consultation exercise conducted by the ONS confirmed that the environmental goods and services sector is central to the objectives of a number of central government departments as well as the devolved governments and data is required to monitor progress and measure success. The Department for Business, Innovation and Skills published The Path to Strong, Sustainable and Balanced Growth ${ }^{16}$ in November 2010 and is working with the Department for Environment, Food and Rural Affairs and the Department of Energy and Climate Change to develop a Roadmap to a Green Economy ${ }^{17}$ Other policy examples include $A$ Green Jobs Strategy for Wales published by the Welsh Assembly Government. ${ }^{18}$ Other organisations, including academia, have identified a need for access to micro data for modelling and cost-benefit analyses.

There have been valuable developments in statistics in response to the keen political interest and a key success criterion for the feasibility study will be to understand and build on the lessons of this work whilst seeking to avoid any duplication of effort. A key example is the Innovas study ${ }^{19}$ commissioned by the Department for Business, Enterprise and Regulatory Reform (now Business, Innovation and Skills) titled Low Carbon and Environmental Goods and Services, an industry analysis. (Innovas, 2009). 
The Low Carbon and Environmental Goods and Services sector (LCEGS) is defined in the report as covering environmental products and activities, renewable energy and emerging low carbon activities such as alternative fuels, building technologies, nuclear power and carbon finance. It covers company activity for the whole environmental supply chain, making the distinction between LCEGS specialists such as manufacturers of wind turbines and suppliers to the LCEGS markets such as manufacturers of gear boxes used in wind turbines.

This study included regional analyses and international comparisons and the Update for 2008/920 valued the Low Carbon and Environmental Goods and Services sector (LCEGS) at £112 billion, positioning the UK as the world's sixth largest low carbon and environmental economy. (Innovas, 2010). See Table 3.

\section{Table 3 UK market value and employment, LCEGS sector, 2008/09}

\begin{tabular}{lcc}
\hline Sector & Market value (£ billion) & Total employed (thousands) \\
\hline Environmental & 23 & 198 \\
Renewable energy & 29 & 266 \\
\hline Emerging low carbon & 56 & 446 \\
\hline
\end{tabular}

Source: Adapted by ONS from Low Carbon and Environmental Goods and Services, an industry analysis (Innovas, 2010)

The United States is estimated by the same study to be the largest low carbon and environmental economy with a market value of $£ 633$ billion, almost six times the size of the UK.

In April 2010, the US Department of Commerce published their own estimates of the size of the US green economy ${ }^{21}$ using data on shipments/receipts sourced from the official 2007 Economic Census as the key measure of economic activity. The US employ a 'narrow' and 'broad' measure where goods and services are included in the former measure only where there is clear agreement that their primary purpose is that of reducing pollution or conserving energy and resources (defined similarly to environmental protection and resource management as used in the Eurostat framework).

The authors highlight some key challenges which would appear to echo general international experience. They note the difficulty in making comparisons across studies due to differences in definitions and methods and recognise the need for further development, stressing the importance of developing methods based on timely official data sources which support regular monitoring of progress. The challenges of measurement are now explored further. 


\section{Challenges to be examined by the feasibility study}

Early consultation with key UK stakeholders and a review of the Eurostat handbook and UK and international experiences in measuring the environmental goods and services sector have helped identify key issues to be examined as part of the feasibility study. Some of these are introduced here.

The environmental goods and services sector is not a sector in the traditional sense. It is not enough to identify a specific type of institution or a distinct set of industries and sum their activity. The production of environmental goods and services cuts across the whole economy and will often only represent a fraction of an organisation's output, being a secondary or ancillary activity (Table 2).

In identifying environmental goods and services activity, pinpointing industries, based on the Standard Industrial Classification System 2007 (SIC2007) for which the total activity falls within the sector, is only possible in a limited way. For example, sewerage (SIC07 37) would be classified in its entirety to the environmental protection domain of wastewater management. Production of electricity (SIC07 35.11), however, does not separately distinguish electricity sourced from renewables. The ONS stakeholder consultation also identified that users have experienced difficulty in identifying environmentally efficient construction services using the industry classifications. Whilst being consistent with the international NACE Rev.2 to the 4-digit level, the UK SIC2007 does include some additional helpful detail at the 5-digit level, for example, 'environmental consulting services' (SIC07 74.90/1) but this is a fairly isolated case.

Similarly, identifying the environmental goods and services based on product classifications does not provide an exhaustive solution. The PRODCOM (PROducts of the European COMmunity) list is defined by a combination of the NACE Rev.2 and the Classification of Product by Activity (CPA). The UK PRODCOM survey is based on almost 4,000 products and covers 21,500 businesses ${ }^{22}$ and can also be matched with data on the UK's international trade in goods data ${ }^{23}$. HM Revenue and Customs provide trade statistics for over 9,000 commodities using commodity codes from the Harmonised System Nomenclature (HS) ${ }^{24}$ and its EU derivative, the Intrastat Classification Nomenclature $(\mathrm{CN})^{25}$. However, the primary focus of these classification systems has not been to identify environmental goods and whilst the OECD has identified a list of environmental goods ${ }^{26}$ which can be explicitly identified from the HS codes, there are recognised gaps. Another point to note is that all of these coding systems primarily deal with goods. UK stakeholders have also identified problems in using the Standard Occupational Classification (SOC) ${ }^{27}$ to identify green professions and skills. The feasibility study will examine how comprehensive these lists are in the UK context and also seek to identify complementary information for services.

International and UK experience suggests that the use of these classification systems will have to be supplemented by comprehensive research to identify the sector. Sweden ${ }^{28}$, for example, employed a range of sources to identify the sector including their business register, official energy statistics, membership lists of industry specific associations and environmental networks, on-line search engines, the Yellow Pages and conferences and events. The feasibility study will examine the practicality of taking a similar approach and Box 2 suggests some potential sources which could be explored. For the longer term, one of the advantages of developing methodology for the UK based on international standards is that any weaknesses in the infrastructure supporting those 
standards will be widely felt, strengthening any case for future development including influencing future revisions to international classification systems.

\section{Box 2 Possible sources for identifying producers in the UK environmental goods and services sector}

- Inter-Departmental Business Register (IDBR)

- Population for existing surveys and specific questions on surveys .e.g. Environmental Protection Expenditure, Innovation, PRODCOM

- Other statistics e.g. Digest of UK Energy Statistics, Innovas study, regional studies

- Experts from DEFRA, DECC and BIS

- Trade Association memberships

- Memberships of professional organisations

- Journals

- Environmental networks

- Intellectual Property Office - register of patents

- Search engines, Yellow Pages etc.

A second issue, already touched upon, is the treatment of activities in the supply chain. The Eurostat selection criterion is that only main producers are included. Producers supplying components for an environmental good or service are only included if the component has no wider application. Going back to the earlier example of the gear boxes used in wind turbines, their manufacture would only be included if the gear box is used exclusively for this purpose. The activity of selling the final goods and services is also excluded. There are two dimensions to this issue for the feasibility study to examine. Firstly, how practical is it to distinguish the elements of the supply chain and secondly, does this treatment of the supply chain meet the user requirements for the UK. The Innovas study in the UK has taken a more inclusive approach to the supply chain and the consultation exercise carried out by ONS confirmed interest in an approach which would allow users to identify supply chains. The possibility of adapting datasets to meet more than one need will require investigation. This challenge was identified by Statistics Norway ${ }^{29}$ where elements of the supply chain for windmills are important for the Norwegian economy but would not fall within the Eurostat criterion.

Another issue of scope is that of knowing when coverage is complete. As identified, there is no neat classification system in place. The questions will therefore need to be addressed as to when can any database of environmental goods and services and producers be considered exhaustive and how, given the dynamic nature of the sector, can it be effectively maintained over time. The availability of any existing published estimates will provide a useful check, as will consultation with experts on the environmental domains, but it has been suggested there may be a need, for 
example, to develop a demand-side measure based on consumer expenditure to confirm any supply-driven measure.

Expanding on the dynamic nature of the sector, a specific issue exists in relation to adapted goods (Table 2). These goods are unique within the environmental goods and services sector in that they do not directly serve an environmental protection or resource management purpose. These are goods which are less polluting or more resource-efficient than equivalent standard goods performing a similar function. Consider refrigerators as an example. The energy efficiency ratings of refrigerators range from $\mathrm{G}$ to $\mathrm{A}++$. The first step in identifying the adapted goods is to determine which within this range is considered the standard good. Is it everything other than the A++ rated product or is it the best seller? Then there is the issue that what is considered the most resourceefficient product today may be the standard product of tomorrow. When energy labelling was introduced the $\mathrm{A}+$ and $\mathrm{A}++$ ratings did not exist and so $\mathrm{A}$ would have been the most energyefficient option. The feasibility study needs to examine how these goods can possibly be tracked and consider carefully the implications for time series of products ceasing to be classified as adapted goods.

As far as possible, the UK Environmental Accounts make use of existing official statistics. In line with the UK Statistics Authority Code of Practice for Official Statistics ${ }^{30}$ existing data sources and estimation techniques must be evaluated before considering a new survey to ensure proportionate burden on suppliers. Additionally, official data sources should be considered ahead of others. This applies to the measurement of the environmental goods and services sector and is a common approach internationally. Countries such as Canada ${ }^{31}$ and Poland ${ }^{32}$ operated specific surveys or adapted existing surveys to fill any gaps in data and a number of countries have used e-mail or telephone surveys to help with the initial scoping of the sector or to test assumptions, but existing sources have generally been examined as a starting point.

Assuming the producers of environmental goods and services can be identified for the UK, the ability to code these producers in line with the Inter-Departmental Business Register (IDBR) ${ }^{33}$ will facilitate access to a rich source of official survey and administrative data including turnover and employment. The IDBR lists organisations covering 99 per cent of UK economic activity and in $2007 / 8$ provided the sampling frame for 68 ONS surveys to companies and local authorities. In principle, this means that once a methodology can be established, regular updating of time series should be achievable. It is, of course, not quite so straightforward.

Where companies or sectors supply a range of goods and services, environmental and nonenvironmental, the make-up of the company or sector needs to be understood in order to assign the relevant turnover to the environmental goods and services sector. This confirms the importance of effectively identifying those operating in the sector and how their business activity breaks down but it also highlights that a degree of estimation will be required - at sector, enterprise, individual site or product level. The feasibility study will explore the relative merits of the different methodologies available. Internationally, turnover would seem to be the most readily available of the variables and is often used as a proxy for allocating other variables such as employment and value added. Assumptions regarding the link between turnover and other variables will be tested for the UK. 
The potential levels of estimation involved in measuring the environmental goods and services sector means that a transparent assessment of the resulting statistics will be very important. UK users have identified that they would be seeking to develop models to forecast the potential growth of the sector and in addition to the data requirements of the Eurostat pilot questionnaire, there is a clear demand in the UK for regional statistics. The feasibility of regional statistics would have to be explored but if it is possible to produce estimates, sufficient metadata would need to be presented to convey the fitness for purpose of the statistics.

As well as regional statistics, UK users have identified a need for statistics on the number and size of businesses in the sector and also specific domains of interest which are not drawn out by the Eurostat framework, for example, activity specific to renewable energy and recycling.

These additional requirements also highlight a final statistical issue that will be examined by the feasibility study. Assuming effective implementation of the proposed international standards, a very detailed dataset would potentially be available on the environmental goods and services sector but what would this tell us? There is a danger of information overload and so it is important to revisit the requirement for an evidence base. The consultation exercise identified the need for key statistics and indicators to understand the size of the sector, the number of companies operating in the sector and its relative contribution to the economy. Users want to compare the relative profitability and productivity of the environmental and non-environmental sectors and to understand the international competitiveness of the UK and the potential for growth, particularly in relation to jobs. Linked to this is an interest in innovation and levels of research and development. This means that in addition to compiling the dataset, ONS must deliver clear analyses for UK users.

As has been demonstrated, there are a wide range of demands for statistics and a series of difficult challenges to be worked through. The ultimate challenge of this feasibility study will be to work with key users to prioritise the work programme within the resources available. It is clear, based on international experience, that the feasibility study should be viewed as a starting point in measuring the environmental goods and services sector.

\section{Conclusion}

There is a clear requirement in the UK, and internationally, to measure the progress towards a green economy, and within this to understand the contribution of the environmental goods and services sector to the growth of the economy. The UK feasibility study to measure this sector in line with proposed international standards faces a number of interesting statistical challenges and it is certain that any initial estimates produced could come with caveats. The programme of work required to address outstanding issues will be presented alongside any preliminary estimates and the lessons learned reported to Eurostat to inform future development. 


\section{Acknowledgements}

The feasibility study introduced by this article benefits from funding by the European Commission, DG Environment and Eurostat by means of a grant agreement. The results of the feasibility study will be published in the UK following sign off of the final report by Eurostat.

Thanks also to those listed for responding to the stakeholder questionnaire issued this summer and for their continued willingness to share their experience and expertise with this project:

Brian Stockdale, Department for Business, Innovation and Skills

Tim Everett, Department for Environment, Food and Rural Affairs

Glyn Jones, Welsh Assembly Government

Wendy McKinley, Department of Environment, NI

James Gillan, Department of Enterprise, Trade and Investment, NI

Professor Max Munday, BRASS, Cardiff University

Sheila Ward, Forestry Commission

Stephen Herbert, Natural England

Stuart Homann, Environment Agency

\section{Notes}

1. ONS consultation on the strategy for the UK Environmental Accounts, www.ons.gov.uk/about/consultations/consultation-on-the-strategy-for-the-uk-environmentalaccounts/index.html

2. Spending Review 2010, www.hm-treasury.gov.uk/spend_sr2010_documents.htm

3. Prime Minister speech to CBI, www.cbi.org.uk/pdf/20101025-cbi-pm-conference-speech.pdf

4. Eurostat, European Commission (2009), Methodologies and Working Papers, The Environmental Goods and Services Sector, http://ec.europa.eu/eurostat/portal/page/portal/product_details/publication?p_product_code=KSRA-09-012

5. Eurostat, European Commission (2009), EGSS Trial Data Collection 2009, www.eurostat.ec.europa.eu/portal/environmental_accounts/methodology/data_collections 6. Obst C, SEEA Editor, Department of Economic and Social Affairs, Statistics Division, United Nations, Outcome Paper for Global Consultation, Issue 5: Environmental Goods and Services Sector (2010), http://unstats.un.org/unsd/envaccounting/seearev/OCdocs/Outcome5.pdf

7. UN System of National Accounts, http://unstats.un.org/unsd/sna1993/toctop.asp

8. CEPA, http://ec.europa.eu/eurostat/ramon

9. CReMA, p.45, http://ec.europa.eu/eurostat/portal/page/portal/product_details/publication?p_product_code=KSRA-09-012

10. NACE Rev.2, http://ec.europa.eu/eurostat/ramon

11. www.statistics.gov.uk/methods_quality/sic/downloads/sic2007explanatorynotes.pdf

12. UK Environmental Accounts, www.statistics.gov.uk/focuson/environmental

13. UK National Accounts - The Blue Book, www.statistics.gov.uk/downloads/theme_economy/bluebook2010.pdf

14. www.stiglitz-sen-fitoussi.fr/documents/rapport_anglais.pdf 
15. www.ons.gov.uk/about/newsroom/statements/national-statistician-launches-well-beingdebate.pdf

16. www.bis.gov.uk/assets/biscore/corporate/docs/p/10-1296-path-to-strong-sustainable-andbalanced-growth

17. Roadmap to a Green Economy http://ww2.defra.gov.uk/environment/economy

18. Welsh Assembly Government, Capturing the Potential: A Green Jobs Strategy for Wales

(2009), www.wales.gov.uk/topics/businessandeconomy/publications/greenjobs/?lang=en

19. Sharp J, Innovas Solutions, Report commissioned by BERR (2009), Low Carbon and

Environmental Goods and Services: An Industry Analysis. www.berr.gov.uk/files/file 50253.pdf

20. Innovas Solutions, Report commissioned by BERR (2010), Low Carbon and Environmental

Goods and Services: An Industry Analysis , Update for 2008/09,

www.bis.gov.uk/assets/biscore/corporate/docs///10-795-low-carbon-goods-analysis-update-200809.pdf

21. U.S Department of Commerce, Economics and Statistics Administration (2010), Measuring the Green Economy, www.esa.doc.gov/GreenEconomyReport.pdf

22. PRODCOM, www.statistics.gov.uk/statbase/Product.asp?vlnk=15281

23. www.uktradeinfo.com

24. HS 2007, http://ec.europa.eu/eurostat/ramon

25. CN 2011, http://ec.europa.eu/eurostat/ramon

26. OECD environmental goods list, www.oecd.org/dataoecd/44/3/35837840.pdf

27. Standard Occupational Classification, www.ons.gov.uk/about-

statistics/classifications/current/soc2010/index.html

28. Brolinson H, Cederlund M, Eberhardson M, Statistics Sweden (2006), Environmental Goods and Services Sector in Sweden 2002-2005,

http://epp.eurostat.ec.europa.eu/portal/environmental_accounts/publications/monetary_environme ntal_accounts

29. Statistics Norway (2008), Environmental Accounts, Environmental Goods and Services Industry and Environmental Expenditures Statistics, 2008 Final Technical Implementation Report to Eurostat,

http://epp.eurostat.ec.europa.eu/portal/environmental_accounts/publications/monetary_environme ntal_accounts

30. www.statisticsauthority.gov.uk/assessment/code-of-practice/index.html

31. Summary of Statistics Canada methodology, p.90, Eurostat handbook, http://ec.europa.eu/eurostat/portal/page/portal/product_details/publication?p_product_code=KSRA-09-012

32. Central Statistical Office of Poland (2008), Environmental Goods and Services Sector, Final Report from Pilot Project conducted under Eurostat-CSO agreement No. 71401.2007.0142007.496,

http://epp.eurostat.ec.europa.eu/portal/environmental_accounts/publications/monetary_environme ntal_accounts

33. Office for National Statistics, Inter-Departmental Business Register, www.statistics.gov.uk/idbr/idbr.asp 


\section{Contact}

Environment.accounts@ons.gov.uk

\section{References}

Eurostat, European Commission (2009), Methodologies and Working Papers, The Environmental Goods and Services Sector, http://ec.europa.eu/eurostat/portal/page/portal/product_details/publication?p_product_code=KSRA-09-012

Innovas Solutions (2010), Report commissioned by BERR (2009), 'Low Carbon and Environmental Goods and Services: An Industry Analysis', www.berr.gov.uk/files/file 50253.pdf

Leinen J (2010) Draft Report on the Proposal for a Regulation of the European Parliament and of the Council on European Environmental Economic Accounts (2010/0073 (COD), European Parliament Committee on the Environment, Public Health and Food Safety, www.europarl.europa.eu/meetdocs/2009_2014/documents/envi/pr/830/830779/830779en.pdf

OECD (2010), Interim Report of the Green Growth Strategy: Implementing our Commitment for a Sustainable Future (May 2010),

www.oecd.org/document/3/0,3343,en_2649_37465_45196035_1_1_1_1,00.html 